\title{
A Research Study into the impact on Emotional Stability of a Transactional Analysis Training Programme intended to develop increased levels of Adult Ego State in Adolescents in Syria
}

\author{
(C) 2020 Alaa MHD Taysir Morad
}

\begin{abstract}
A research study is described into the impact on Adult ego state and emotional stability of 36 adolescent students (with 36 in a control group) of a training programme based on transactional analysis concepts run in a school in Damascus. An experimental battery of instruments comprised existing and new instruments including an Ego-State Wheel, an Ego State Problem-Solving Scale, an Ego State Measure, the Emotional Stability Brief Measure, and the Geneva Emotion Wheel. Results showed differences in Adult and Free Child ego states and emotional stability, and some differences between boys and girls on Nurturing Parent and Adapted Child ego states.
\end{abstract}

\section{Key Words}

Transactional analysis education, adolescence, Geneva Emotion Wheel, Ego-State Wheel, Ego State Problem-Solving Scale, Ego State Measure, Emotional Stability Brief Measure, Adult ego state

\section{Introduction}

Transactional Analysis (TA) has extended from its origins as a psychotherapeutic approach and now has wide application in organisational, educational and coaching/counselling contexts. Originally referring to the interactions, or transactions, between people, the term TA now encompasses a wide range of other interlocking concepts. Its use in terms of teaching it to young people is now well established and there have been various research studies published about its impact although none in Syria (Alsalhe, 2005- Iraq; Mahmoud, 2010 - Iraq; Seghati, Shafiabady, Sodani and Akbari, 2014 - India; Kulaskekara, 2015 - India; Keshavarzi, Azar, Mirnasab and Gargari, 2016 - Iran; Netrawati, Furqon, Syamsu Yusuf, and Nandang Rusmana, 2016 - Indonesia).

There is also an international scheme established referred to as the TA Proficiency Awards is TAPA), and this operates for children and young people (TAPACY), for parents and caregivers (TAPACP), and for other groups associated with the development of children (Hay \& Widen, 2015). Those responsible for the TAPA schemes also issue a Handbook of Teaching Suggestions (Hay, 2017) which formed the basis for designing a training programme for adolescents at a school in Damascus.

The decision to teach TA was also influenced by the need to develop the emotional stability of the young people. Whitley-Hunter (2016) sampled four studies that linked transactional analysis to what he referred to as emotional intelligence, using Mayer and Salovey's (1997) four-branch ability model of perceive, use, understand, and manage emotions. Steiner (Steiner, 1984; Steiner with Perry, 1997) has written of emotional literacy as the ability to understand one's own feelings and to empathise with others, and provides a self-help training programme. For this study we chose to use the term emotional equilibrium, as defined below as one of our research terms.

Rudolph (2002) has pointed out that the transition through adolescence is accompanied by biological, psychological and social challenges. Graham (2003) comments on the turbulent physical changes, energy levels, higher needs for sleep, activity, sexual relations, music, philosophical questions, attitudes and sexual identity, displays of rebellion, breaking of rules, and balancing of values or separating them from needs.

It was considered that emotional stability might be developed in young people through teaching them about transactional analysis, and particularly about ego states. The research study was set up so that there would be a control group; in this way it would be possible to use various measures (as detailed below under Methodology) and establish whether the 
teaching of TA did indeed influence both emotional stability and the ego state patterns of the young people.

\section{Literature Review}

An extensive review of TA literature was conducted, as will be seen in the Bibliography. Guidance in terms of design of the training programme was also obtained from the Handbook of Teaching Suggestions for the international scheme of TA Proficiency Awards for Children (Hay, 2017).

It was concluded that the ego states are a conscious part of the personality, manifested through the behaviour of the individual, and affecting their feelings and thoughts. The ego states can be observed and measured, are adjustable and linked to mental health and personal maturity regardless of the age of the individual.

Material related to emotional stability is described below in the section about research instruments used. It was concluded that emotional stability, like ego states, is an essential component of personality, related to emotional, cognitive and behavioural structures. It requires constant movement to stay in balance, is formed as part of character traits in childhood, becomes semi-static in late adolescence but remains adjustable.

In terms of adolescence, it was concluded that it consists of three regenerative episodes that allow more extensive growth than the earlier childhood development of the Child, Adult and Parent ego states. Previously existing needs are increased and new needs emerge, the personality expands and becomes more coherent, clearer, changed and developed.

A previous study in Iran by Keshavarzi et al (2016) was of particular relevance, although in that case the measure used was the Regulation of Emotions Questionnaire, a self-report developed by Philips and Power (2007), although the same questionnaire was not used in this study.

\section{Research Methodology}

Research Terms

Transactional Analysis: " ... is a social psychology developed by Eric Berne, MD (d.1970). Berne's theory consists of certain key concepts that practitioners use to help clients, students, and systems analyze and change patterns of interaction that interfere with achieving life aspirations" (ITAA, 2019). It is used in this paper to refer to the collection of concepts that were incorporated into the training programme provided for the young people.

Transactional Analysis Proper: this term is nowadays used to refer to analysis of interactions; the original use of the term by Berne was when he was identifying the 'transactions' in terms of which ego states in one person are communicating with which ego states in another person.

Adult: Tudor (2003) describes what he refers to as "an expansive Adult ego state which characterises the pulsating personality, processing and integrating feelings, attitudes, thoughts and behaviours appropriate to the here-and-now - at all ages from conception to death. (p.201). This lines up with the definition from Kuijt (1978) who questionnaire was used: "The Adult ego state is characterized by an autonomous set of feelings, attitudes and behavior patterns which are adapted to the current reality .(p.5).

Emotional Equilibrium: Scherer (2005) defined emotion as "an episode of interrelated, synchronized changes in the states of all or most of the five organismic subsystems in response to the evaluation of an external or internal stimulus event as relevant to major concerns of the organism." (p. 679). For emotional equilibrium, or stability, we combined this with Halaweh, Willén, \& Svantesson's (2016) reference to "the balance and control of emotions and deal flexibly with the situations and events of the current and new, which increases the ability to lead positions and others." (p. 7).

Adolescence: Makhoul (2003) defined adolsescence as "a period of comprehensive growth during which a person moves from childhood to adulthood. Adolescence is the stage of preparation for adulthood that extends from the second decade in the life of the individual, from the age of 13 to the age of 21 or a year or two later. (p. 266)

\section{Research Questions}

1. Does the training programme have a developmental impact on personality? Does it reflect on any of the ego states?

2. More specifically, does the TA element of the training programme lead to the development of Adult ego state and increased emotional stability of adolescents?

Research Hypotheses

That there will be statistically significant differences between the average scores of the experimental group students, in the pre-and post-tests, on the ego state and emotional equilibrium scales.

That there will be statistically significant differences between the average scores of the experimental and the control groups in the post tests of the ego state and emotional equilibrium scales.

That there will be statistically significant differences between the average scores for boys and girls on the pre-and post-tests of the ego state and emotional equilibrium scales, and that these will occur for the experimental and the control groups. 
That there will be statistically significant differences between the average scores for students in the 8th (13 years) and $10^{\text {th }}$ (15 years) grade on the pre-and posttests of the ego state and emotional equilibrium scales, and that these will occur for the experimental and the control groups.

The null hypotheses are that any of the statistically significant differences described above will not occur.

\section{Research Subjects}

A random sample of 250 adolescents (150 boys and 100 girls) from two schools were invited to complete the Geneva Emotion Wheel and the Ego State Wheel (as described below). At the end of this process, 90 subjects (36 boys and 46 girls) were selected based on them having high and mid scores on the Geneva Emotion Wheel and high scores for Parent and Child and low scores for Adult on the Ego State Wheel (see below for descriptions of these instruments). These students were given an invitation to attend a training programme that would provide them with information about the questionnaire content. The intention was to have voluntary and enthusiastic participation in the pilot study. Students who had expressed an interest were given a brief idea of the purpose, duration and content of the training and were asked to discuss the decision with their parents.

Details of academic achievement for these 90 students were also checked to ensure that we had a mix of low, middle and high achievers. Later, some students were eliminated from the research results due to lack of preand post-tests.

As shown in Table 1, a sample of 72 students, aged 13-16 years, were included, and randomly assigned into matched experimental and control groups of 36 subjects each. The experimental group was further divided into three groups: 11 boys in early adolescence (11-14 years), 12 boys in middle adolescence (15-18 years), and 13 girls in early and late adolescence (11-14 years, 18-21 years).

The mixed ages for the group of girls arose because there were not enough in the same age group to form a group suitable for the lessons; it was also noted that the female group was quieter and more attentive than the boys during the sessions.

\section{Research Tools}

An experimental battery of instruments were used:

\section{Geneva Emotion Wheel (GEW)}

The Geneva Emotion Wheel (GEW) (see Scherer, 2005; Scherer, Shuman, Fontaine \& Soriano, 2013) is a theoretically derived and empirically tested instrument to measure emotional reactions to objects, events, and situations. Designed by a well-equipped research group comprising experts from the Swiss National Research Center, the Swiss National Center for Emotional Sciences, and the German Karl-Benz Foundation, it is based on broad emotional terms expressed by individuals of different ages in German, French and English languages. GEW $3^{\text {rd }}$ edition (Swiss Center for Affective Sciences, 2018), consisting of four axes with five phrases each), was used; agreement was given by the Swiss Center for Emotional Sciences to translate the Wheel into Arabic.

Respondents are asked to indicate the emotion they experience by choosing intensities for a single emotion or a blend of several emotions out of 20 distinct emotion families. The emotion families are arranged in a wheel shape with the axes being defined by two major dimensions of emotional experience: five degrees of intensity are possible, represented by circles of different sizes, with additional options of None - no emotion felt, and Other - different emotion felt.

GEW was used because the items cover the crosscultural psychological variables identified by Tameh and Aghaei (2014), and are consistent with the distribution of emotions according to Chander \& Chaturvedi's (2010) global emotional balance of measure in the United States on five axes: pessimism versus optimism, apathy versus empathy, dependence versus autonomy, anxiety versus calm, aggression versus tolerance).

The GEW was given to the 250 students before the project began, and again at the end to the students in the experimental and control groups.

\begin{tabular}{|c|c|c|c|c|c|c|}
\hline Total & \multicolumn{3}{|c|}{ Control 36} & \multicolumn{3}{|c|}{ Experimental 36} \\
\hline & $f$ & $\mathrm{~m}$ & \multirow{2}{*}{$\begin{array}{l}\text { early adolescence born } \\
\text { 2003-2004 }\end{array}$} & $f$ & $\mathrm{~m}$ & \multirow{2}{*}{$\begin{array}{l}\text { early adolescence born } \\
\text { 2003-2004 }\end{array}$} \\
\hline 36 & 6 & 11 & & 6 & 11 & \\
\hline 36 & 7 & 12 & \multirow{2}{*}{$\begin{array}{l}\text { middle adolescence born } \\
\text { 2001-2002 }\end{array}$} & 7 & 12 & \multirow{2}{*}{$\begin{array}{l}\text { middle adolescence born } \\
\text { 2001-2002 }\end{array}$} \\
\hline 72 & 13 & 23 & & 13 & 23 & \\
\hline
\end{tabular}

Table 1: Experimental and Control Group Details 


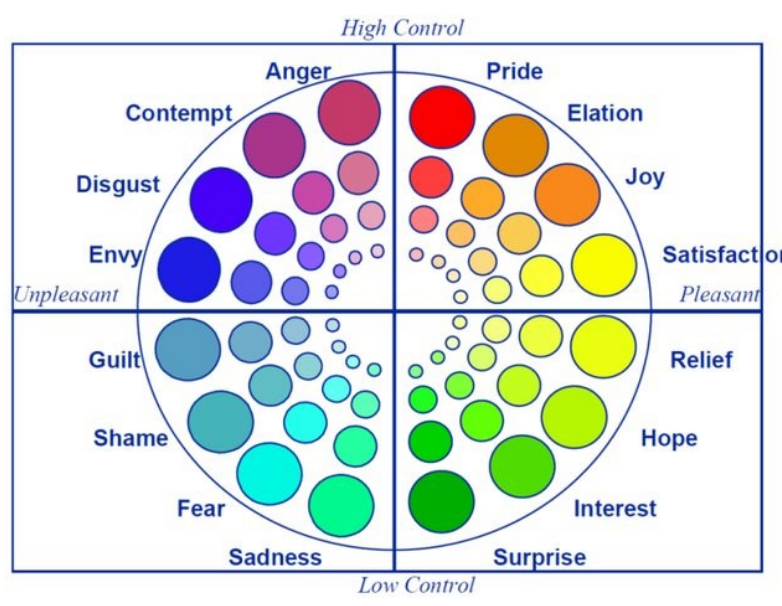

Figure 1: Example Geneva Emotion Wheel Protoype (Sacharin, Schlegel \& Scherer, 2012)

\section{Ego state wheel (ESW)}

Designed by the author, the Ego State Wheel (ESW) was based on the GEW approach and the contents of the monitoring lists of Kuijt (1978), which include a set of simple and clear characteristics that require the researcher to estimate the intensity of each attribute on a five-dimensional scale. Although there are newer tests, this list is clear, concise and easy to apply, especially for adolescents. It is very similar to modern standards, but covers more profound themes in theory in a clear and simple way. The translation of these items was audited.

The ESW therefore covered 60 attributes, across ego states as shown in Table 2. It had a high Alpha Cronbach of 0.86 .

The ESW was given to the 250 students before the project began, and again at the end to the students in the experimental and control groups.

\section{Ego State Problem-Solving Scale}

Prepared by the researcher, the Ego State ProblemSolving Scale (ESPSS) presented 24 example problems with the choice of three solutions, reflecting ways of interacting that are perceived to be associated with the Parent, Adult and Child ego states of the young person. Alpha Cronbach was 0.69. This test was designed to study the potential increase of Adult ego state problem-solving and was applied to the experimental and control groups before and at the end of the training.

\section{Ego State Measure (ESM)}

Because the ESW is a new and abbreviated instrument using single words (dominant, obsessed, etc), a second test of ego states using 30 of the most prominent phrases from previous global tests was adopted, on the basis that the phrases may be more explanatory than the word. This was used in pre- and post-measurement with the experimental group only.

\section{Emotional Stability Brief Measure (ESBM)}

The ESBM (Halawah, 2016) scale contained 19 items and had been recently used with a sample of adolescent secondary school students in Syria. It presents as a brief form for measuring emotional equilibrium through two main axes (emotional control and self-esteem). The ESBM was used for the experimental group as a tool for pre and post test.

\section{Training Design}

The training programme was designed by the author, taking into account the proposed TAPACY syllabus and the SEAL (DFeS, 2007) programme, a curriculum resource introduced in the UK to help primary schools develop children's social, emotional and behavioural skills. The concepts covered in the programme are

\begin{tabular}{|c|c|}
\hline OK Nurturing Parent(ONP) 5 item & 5 item OK Controlling Parent CP \\
\hline 0 item (NP) Nurturing Parent(OCP+ONP=NP) \\
\hline Not-OK Nurturing Parent 5 item & Not-OK Controlling Parent 5 item \\
\hline 10 item Controlling Parent(NONP+NOCP=CP) \\
\hline Experiencing Adult 10 item & Computing Adult 10 item \\
\hline \multicolumn{2}{|c|}{20 item Adult (A) } \\
\hline Natural Child (NC ) 5 item & Little Professor (LP) 5 item \\
\hline \multicolumn{2}{|c|}{10 item Free Child (LP + NC =FC) } \\
\hline Compliant Child (CC) 5 item & 5 item Rebellious Child (RC) \\
\hline
\end{tabular}

Table 2: The Ego State Wheel Attributes 
shown in Table 3. The 20 training sessions lasted $40-$ 45 minutes and were run over a three-month period and the programme was refereed by Professors of the Faculty of Education, University of Damascus.

\begin{tabular}{|l|l|}
\hline \multicolumn{2}{|l|}{ Transactional Analysis Concepts } \\
\hline Session 1 & Ego states/Modes \\
\hline Session 6 & Transactions \\
\hline Session 7 & Life positions \\
\hline Session 10 & Drama triangle \\
\hline Session 14 & Strokes \\
\hline Session 15 & Script \\
\hline Session 16 & Time structuring \\
\hline Social and emotional aspects of learning (SEAL) \\
\hline Session 8 & Social skills \\
\hline Session 9 & Assertiveness \\
\hline Session 13 & Managing feelings \\
\hline Session 17-18 & Motivation \\
\hline Sessions 19-20 & Social skills \\
\hline
\end{tabular}

Table 3: Session Concepts

Editor's Note: There are no internationally qualified transactional analysts in Syria so it was not possible to confirm the accuracy of the teaching; however it seems unlikely that any theoretical misunderstandings would have been significant enough to cause a problem with the young people.

Student Evaluation

In addition to the research instruments that required the researcher to observe and assess the students, careful notes were kept about the behaviours of individual students and their reactions with others during the sessions. For example: Ahmed today a lot of laughter and movement is unusual... Nour reacted in most of the exercises or was very critical in her observations ....

Implementation

The stages of implementation are illustrated in Figure 2:

Stage 1:250 (150 boys, 100 girls) adolescent students completed the GEW and ESW and a selection made of 90 who were offered the option of a training programme.

Stage 2: the 72 finally selected were assigned to experimental and control groups of 36 . The experimental group then completed the ESM and ESBM
Stage 3: the experimental group of 36 were divided into classes and taught the concepts indicated in Table 3; no further action was taken with the control group until the final post-testing.

Stage 4: post-tests were administered: the GEW and ESW to all students; the ESM and EBSM were used with the experimental group only.

Stage 5: results were analysed (and follow-up sessions were conducted for the Control group).

\section{Ethical Considerations}

When distributing the initial forms, the author introduced herself as a research student who wanted to know the student's opinions of their own personal qualities, in order to study psychological variables among students. They were reassured that their answers would be confidential and would be converted into digital data. They were free to decide whether they wished to participate or not; there was also an option box at the end of the questionnaire for them to indicate whether they might be interested in participating in a series of subsequent sessions. The author explained that a random selection would be made of those who wished to attend the subsequent sessions; this would not be affected by their answers to the questionnaires, for which they were advised there were no right or wrong answers.

When the final selection of the experimental group had been made, those students were provided with a brief idea about the structure of the training (number of sessions, duration, purpose, conditions), and advised that the intention was to provide some scientific proof of the usefulness of developmental training for adolescents using an approach that has been applied in schools and universities in many countries in the world.

They were asked to check that attending the sessions would not conflict with their homework requirements, and to discuss their attendance with their family before they made a decision. One student who had indicated his interest in attending the sessions withdrew his request after this.

This process was kept completely confidential so that the individual results, and the individual actions, would have no impact on the students in relation to their attendance at the school.

\section{Results}

More detailed information about the results, including tables, can be accessed within the author's thesis (in Arabic) (Morad, 2018), which can be accessed at https://taresearch.org/publications/. There is also a summary of the thesis in English at the same place. 


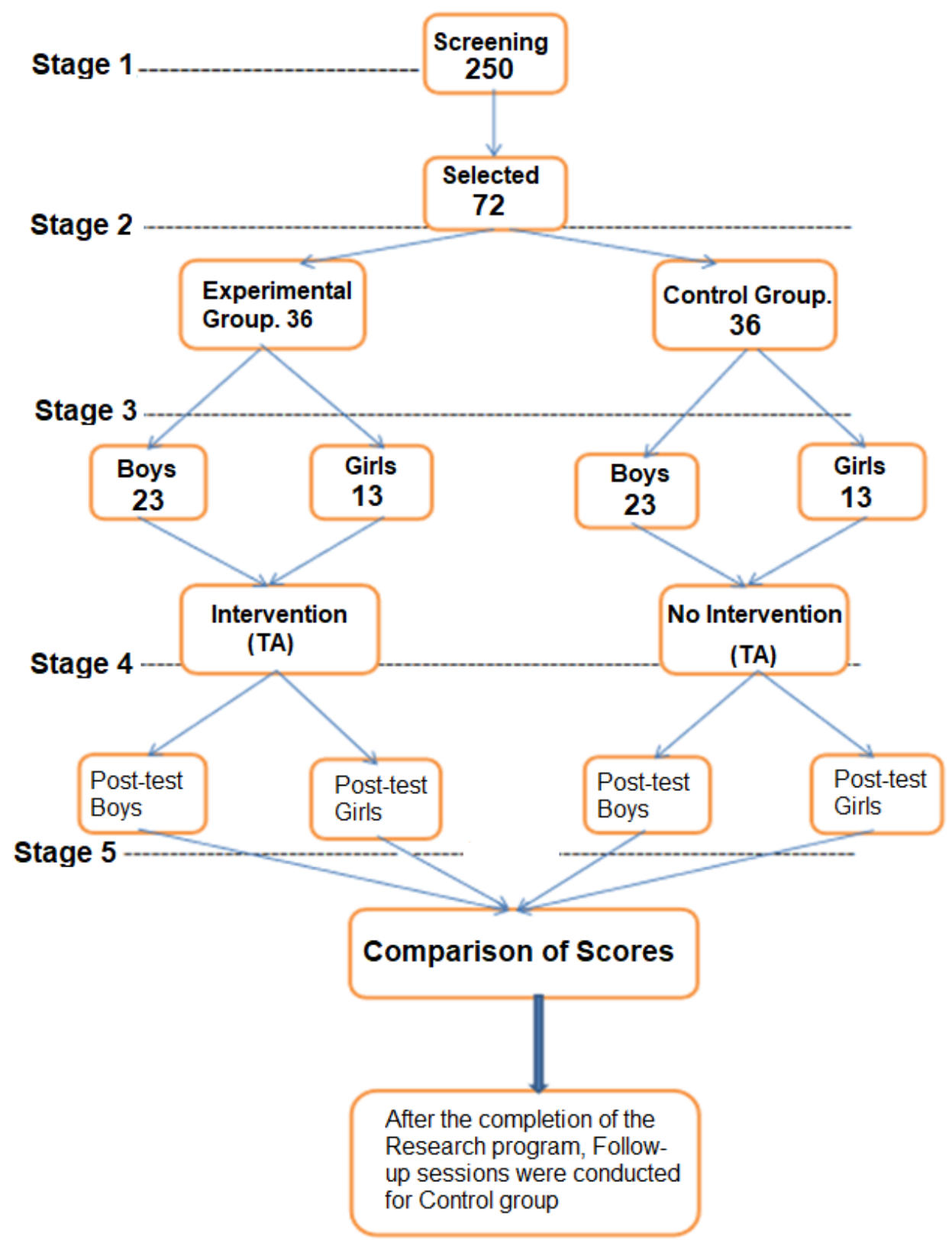

Figure 2: Schematic Representation of the Research Design

Summary results of the study were:

1. There are simple developmental differences on most variables of the research, especially the Free Child, Adult Ego State and positive feelings.

2. Training has had a slight developmental effect on most ego states, especially Adult and Free Child. This development continued after training in the delayed test. Development indicators maintained their values with a slight decrease of only $4 \%$. This means that the training achieved a developmental effect ranging from $2-10 \%$.
After 45 days, this effect remained more than $95 \%$ above its level.

3. There are statistically significant differences between the average scores of the experimental and control groups in the post-test on the scale of the Adult and Free Child.

4. There are statistically significant differences between the average scores of the experimental and control groups in the post-test on the positive feelings dimension, and an absence of differences on the negative feelings, on the Geneva Emotion Wheel. 
5. There are statistically significant differences between the average pre- and post-test scores of the experimental group students on Adult and Free Child, which can be attributed to the programme.

6. There are statistically significant differences between the average pre- and post-test scores of the experimental group students on positive and negative feelings on the Geneva Emotion Wheel and the Emotional Stability Brief Measure, which can be attributed to the programme .

7. There are statistically significant differences between the average post-test scores of the experimental and control group individuals in the Ego State Problem Solving Scale in favour of the experimental sample, which can be attributed to the programme.

8. There was an absence of any significant differences between the eighth and tenth grade students in the post test of the ego states and emotional stability variables.

9. There are differences attributable to gender on the variables of Nurturing Parent Ego State for girls in the pre-test, and no significant differences attributable to gender on the Emotional Stability Brief Measure.

10. There are no statistically significant differences between the average pre- and post-test scores of the control group students on the variables of the ego states and the emotional stability.

\section{Limitations}

An obvious limitation is that this research was conducted in Syria, with adolescents, so may not be transferable to other countries or with other age groups.

The teacher/researcher had no formal qualifications in transactional analysis and no access to TA training run by internationally accredited trainers. It was not feasible to check the standard of the teaching to the experimental group, although TA concepts are robust enough that they are usually of value even when presented by an unqualified person.

Apart from the GEW, the instruments used have not been validated.

\section{Conclusion}

The results of the study indicate that it is likely to be beneficial to provide training based on TA concepts within primary and secondary schools, and specifically for the various age groups of adolescents.
This would require training teachers and school superintendents in schools in TA concepts including the use of educational activities.

Further research is suggested to:

- Construct standardized tests of ego states in Syria.

- Conduct similar studies with different samples of children and their parents.

- Correlative studies to discover the internal relationships between ego states and non-TA personality variables.

Alaa MHD Taysir Morad PhD (Developmental Psychology) is a lecturer at Damascus University Faculty of Education and a psychotherapist in a medical clinic and with the Syrian Arab Red Crescent humanitarian organisation. She can be contacted at Alaamorad1@gmail.com.

\section{References}

Alsalhe (2005) The effect of transactional analysis on reducing the level of emotional deprivation among middle school students 2004-2005 Iraq: Author https://uomustansiriyah.edu.iq/media/library/dissertations/23 81.pdf accessed 19 October 2019

Chander, M. \& Chaturvedi, R (2010). Development of emotional stability scale. Industrial psychiatry Journal, 19(1),pp 37-40. https://doi.org/10.4103/0972-6748.77634

DFES (2007). Social and Emotional Aspects of Learning (SEAL): Guidance Booklet. Nottingham: DfES

Graham. J. (2003). Cycles of Development. Family Issues 11: 2, 1-16 (published by University of Maine Cooperative Extension)

Halawah, Yasmin (2016) Emotional balance and its relationship with self-esteem: A field study on a sample of secondary vocational education students in the province of Damascus. Unpublished masters thesis in educational psychology. Damascus: Damascus University Faculty of Education, Department of Psychology

Halaweh, H., Willén, C., \& Svantesson, U. (2017) Association between physical activity and physical functioning in community-dwelling older adults, European Journal of Physiotherapy, 19:1, 40-47, DOI: $\underline{10.1080 / 21679169.2016 .1240831}$

Hay, J. (2017) Teaching Suggestions: Transactional Analysis Proficiency Awards http://www.instdta.org/taproficiency-awards.html accessed 19 October 2019

Hay, Julie \& Widen, Ulrika (2015) The Transactional Analysis Proficiency Awards: A Social Action Initiative Transactional Analysis Journal 45:3 204-216 https://doi.org/10.1177/0362153715601399 
ITAA (2019). International Transactional Analysis Association https://www.itaaworld.org/what-transactionalanalysis.

Keshavarzi, S., Azar, E. F., Mirnasab, M. M., \& Gargari, R. B. (2016). Effects of a Transactional Analysis Program on Adolescents' Emotion Regulation. International Journal of Psychological Studies, 8(4), 51-59.

https://doi.org/10.5539/ijps.v8n4p51

Kuijt.J.D.(1978). Transactional Analysis Ego States: Subdivisions And Definions Determined by Latent Partition Analysis. MSc Thesis submitted. Vancouver: University Of British Columbia.

Kulashekara, B.(2015). Impact of Transactional Analysis on Parent-Adolescent conflict, Aggression and Depression among Adolescent Students. PhD Thesis.

Manasagangothri: Department of Studies in Psychology, University of Mysore.

Mahmoud, Kamila Shakir (2010) Effectiveness of the Mentoring program in the Organization of Ego States among the Students of the Colleges of Education -University of Tikrit - dissertation: Author http://search.shamaa.org/home?page=Search\&SearchValue TBX=\%D8\%AC\%D8\%A7\%D9\%85\%D8\%B9\%D8\%A9\%20 \%D8\%AA\%D9\%83\%D8\%B1\%D9\%8A\%D8\%AA\%20(\%D8 \%A7\%D9\%84\%D8\%B9\%D8\%B1\%D8\%A7\%D9\%82)\%D9\% 83\%D9\%84\%D9\%8A\%D8\%A9\%20\%D8\%A7\%D9\%84\%D8 \%AA\%D8\%B1\%D8\%A8\%D9\%8A\%D8\%A9\&SearchTypeD DL=ExactSubject accessed 19 October 2019

Makhoul, Malik Suleiman. (2003). Childhood and adolescent psychology. I 8, Damascus: University of Damascus Publications Research Methodology https://books. google.com/books?id=zEArDAAAQBAJ\&pg=P A $140 \& \mid p g=P A 140 \& d q=\% D 8 \% B 9 \% D 9 \% 84 \% D 9 \% 85+\% D 8 \%$ A7\%D9\%84\%D9\%86\%D9\%81\%D8\%B3+\%D8\%A7\%D9\%8 4\%D8\%B7\%D9\%81\%D9\%88\%D9\%84\%D8\%A9+\%D9\%88 \%D8\%A7\%D9\%84\%D9\%85\%D8\%B1\%D8\%A7\%D9\%87\% D9\%82\%D8\%A9+\%D9\%85\%D8\%A7\%D9\%84\%D9\%83+\% D8\%B3\%D9\%84\%D9\%8A\%D9\%85\%D8\%A7\%D9\%86+\%D 9\%85\%D8\%AE\%D9\%88\%D9\%84\&source=bl\&ots=d9a787| knb\&sig=ACfU3U2gLaeDD5ynpdHU3i9N1bktgfJzw\&hl=en\&sa=X\&ved=2ahUKEwjXwuTjrfbiAhVt8eAKHfe gCuAQ6AEwDHoECAgQAQ\#v=onepage $\& \mathrm{q}=\% \mathrm{D} 8 \% \mathrm{~B} 9 \% \mathrm{Dg}$ \%84\%D9\%85\%20\%D8\%A7\%D9\%84\%D9\%86\%D9\%81\%D 8\%B3\%20\%D8\%A7\%D9\%84\%D8\%B7\%D9\%81\%D9\%88\% D9\%84\%D8\%A9\%20\%D9\%88\%D8\%A7\%D9\%84\%D9\%85 \%D8\%B1\%D8\%A7\%D9\%87\%D9\%82\%D8\%A9\%20\%D9\% 85\%D8\%A7\%D9\%84\%D9\%83\%20\%D8\%B3\%D9\%84\%D9 \%8A\%D9\%85\%D8\%A7\%D9\%86\%20\%D9\%85\%D8\%AE\% D9\%88\%D9\%84\&f=false accessed 19 October 2019

Mayer, J. D. \& Salovey, P. (1997). What is emotional intelligence? In P. Salovey \& D. Sluyter (Eds). Emotional Development and Emotional Intelligence: Implications for Educators (pp. 3-31). New York: Basic Books

Morad, A MHD T (2018) The Effect of Training Programme based on Transactional Analysis Theory to Develop Adult
Ego State and its Impact on the Emotional Stability of Adolescents .thesis submitted to Damascus University; Author

Netrawati, Furqon, Syamsu Yusuf \& Nandang Rusmana (2016) Solving Adolescent Verbal Aggressions through Transactional Analysis Counseling Approach Journal of Education and Practice ISSN 2222-1735 (Paper) ISSN 2222-288X (Online)Vol.7, No.18, 2016 pp 169-177.

Phillips, K.F.V. \& Power, M.J. (2007) A new self-report measure of emotion regulation in adolescents: The Regulation of Emotions Questionnaire Clinical Psychology \& Psychotherapy 14 (2), 145-156 https://doi.org/10.1002/cpp.523

Rudolph, K.D. (2002) Gender differences in emotional responses to interpersonal stress during adolescence. Journal of Adolescent Health 30(4 Suppl):3-13 https://doi.org/10.1016/S1054-139X(01)00383-4

Sacharin, V., Schlegel K., \& Scherer K. R. (2012). Geneva Emotion Wheel Rating Study. Unpublished report. Swiss Center for Affective Sciences, University of Geneva. 3 (2018-2-7) https://doi.org/10.1037/t36935-000

Scherer, K. R. (2005). What are emotions? And how can they be measured? Social Science Information, 44(4), 693-727. https://doi.org/10.1177/0539018405058216

Scherer, K.R., Shuman, V., Fontaine, J.R.J, \& Soriano, C. (2013). The GRID meets the Wheel: Assessing emotional feeling via self-report. In Johnny R.J. Fontaine, Klaus R. Scherer \& C. Soriano (Eds.), Components of Emotional Meaning: A sourcebook (pp. 281-298). Oxford: Oxford University Press. https://doi.org/10.1093/acprof:oso/9780199592746.003.001 $\underline{9}$

Seghati, T, Shafiabady A, Sodani, M. Akbari, B. (2014). Effectiveness Of Group Training Based On Transactional Analysis in Reducing Loneliness Girl students of High School First Grade in Rasht. Indian J.Sci.Res. 4 (3): 422429 .

Steiner, C (1984) Emotional Literacy. Transactional Analysis Journal. 14:3, 162-173, DOI:10.1177/036215378401400301

Steiner, C. with Perry, P. (1997) Achieving Emotional Literacy. London: Bloomsbury.

Swiss Center for Affective Sciences (2018) https://www.unige.ch/cisa/gew/ accessed 19 October 2019

Tameh, E. A. \& Aghaei, H. (2014). Job Satisfaction and Emotional Stability Among School Teachers: A Cross Cultural Comparison. Journal of Applied Sciences Research. 10:4, 240-249

Tudor, Keith (2003) The Neopsyche: the Integrating Adult ego state in C. Sills \& H Hargaden (eds) Ego States. London: Worth Publishing 201-231 
Whitley-Hunter, B. (2014) Validity of transactional analysis and emotional intelligence in training nursing students. Journal of Advances in Medical Education and Professionalism. 2014 Oct; 2(4): (138-145)

\section{Bibliography}

Included here to indicate further literature references that contributed to the author's understanding of TA concepts and the design of the teaching to the students.

Allen, J. R \& Allen, B. A (1988). Scripts and Permissions: Some Unexamined. Assumptions and Connotations Transactional Analysis Journal 18:4 283-293. https://doi.org/10.1177/036215378801800403

Barrow, G (2007). Teaching, Learning, Schooling, and Script. Transactional Analysis Conference in San Francisco. p6

Barrow, G. Newton, T (2016). Educational transactional analysis. By Florence production Itd, UK. Original 2015 London: Routledge https://doi.org/10.4324/9781315686776

Ciucur, D (2013). The Ego States and the "Big Five" Personality Factors Procedia - Social and Behavioral Sciences 78. $581-585$.

https://doi.org/10.1016/j.sbspro.2013.04.355

Cornell.F.W., de Graaf. A., Newton.T \& Thunnissen. M. (2016). Into TA: A Comprehensive Textbook on Transactional Analysis London: Karnac

Dusay, J. M. (1972). Egograms and the constancy hypothesis. Transactional Analysis Journal, 2, 37- 41 https://doi.org/10.1177/036215377200200313

English, F. (2014). A Summary of Transactional Analysis Concepts I use. Excerpted from "How Did You Become a Transactional Analyst? "Transactional Analysis Journal, 2005, 35,(1), 78-88.

https://doi.org/10.1177/036215370503500110

Freed, A.M (1991). T.A. For TOTS and other prinzes. Rolling Hill Estates CA: Jalmar Prss Inc

Harris. A. Thomas. (2004). I'm OK, You're OK. New York: HarperCollins.

Hawkes, L (2007). The Permission Wheel Transactional Analysis Journal 37, (3),

https://doi.org/10.1177/036215370703700305
Hay, J (2014). Permissions-An Essay.

https://juliehay.org/wp-

content/uploads/2020/01/permissions - an essay.pdf

Hay, J. (2013). Injunctions- an essay https://juliehay.org/wpcontent/uploads/2020/01/injuctions - an essay-1.pdf

Hay, J.(2009). Working it out at work understanding attitudes and building relationships. Second edition, Hertford: Sherwood publishing

Hay, J (2015). Four conceptualizations of the concept of script. IDTA Newsletter 10: 4 3-6

James, M. \& Jongeward, D. (1996). Born to Win: Transactional Analysis with Gestalt Experiments. Reading MA: Addison-Wesley Publishing Company, Inc Johnsson, R. (2011). Transactional Analysis Psychotherapy, Three Methods Describing a Transactional Analysis Group Therapy, Lund University, Department of Psychology. https://doi.org/10.29044/v2i2p3

Karpman, S (1968). Fairy tales and script drama analysis Transactional Analysis Bulletin. 26 (7): 39-43.

Knapp, M.\& Erskine, R.(2010). The script system: an unconscious organization of experience. International Journal of Integrative Psychotherapy, 1 (2), 13- 18.

Levin, P. (2015). Ego States and Emotional Development in adolescence. Transactional Analysis Journal 45(3) 228-237. https://doi.org/10.1177/0362153715599990

Newell, S.\& Jeffery, D. (2013) Behaviour Management in the classroom. London: David Fulton Publishers https://doi.org/10.4324/9780203462300

Steiner, C (2009). The Heart of the Matter: Love, Information and Transactional Analysis. San Francisco: TA Press

Stuart, K. \& Agar, A:(2011). The use of Transactional analysis in Secondary Education: A Case Study. Tean Journal 3 (1), 1-29

Tilney, T (2001). Dictionary of Transactional Analysis. London: Whurr Publishers Ltd.

Tudor. K. \& Summers, G. (2014) Co-creative transactional analysis. London: Karnac Books.

Widdowson, Mark. (2010). Transactional analysis. 100 key points \& techniques. San Bernardino: Routledge https://doi.org/10.4324/9780203868393 